\title{
Energy efficiency of multi-apartment residential houses with individual heat supply
}

\author{
Vladimir Melnikov ${ }^{1}$, Uladzimir Navaseltsau ${ }^{2 *}$ and Dzina Navaseltsava $^{2}$ \\ ${ }^{1}$ Stoletov State University of Vladimir, Institute of Architecture, Construction and Energy, Gorky str., \\ 87, 600000, Vladimir, Russian Federation \\ ${ }^{2}$ Brest State Technical University, Faculty of Engineering systems and Ecology, Maskouskaya str. \\ 267, 224017, Brest, Republic of Belarus
}

\begin{abstract}
Centralized hot water systems widely used in Russia and Belarus are characterized by a considerable length and branching which inevitably leads to increased heat losses and to an unstable hydraulic system. The operation of the domestic hot water system in the circulation mode can be characterized by several parameters; one of which is the specific ratio of the cost of thermal energy for heating a cubic meter of hot water. The parameter is often regulated by law in Russia; exceeding this parameter is considered as administrative violation. The aim of the research is to determine the design and actual costs of thermal energy for hot water supply (hot water heating) and their comparison, analysis of the data obtained. The methodology for determining the design and real costs of thermal energy for hot water supply was to study the operation of the hot water supply system of a residential 144-apartment 9-storey building. The research showed that the actual circulating flow rate is much less than the calculated circulating flow rate. The authors note that in order to optimize the standard for heating a cubic meter of water it is necessary to observe the calculated circulation modes. This will require stabilization of the hydraulic systems of both the external and internal networks which is a difficult but feasible task. The research results are supposed to be taken into account when setting up existing hot water supply systems.
\end{abstract}

Keywords: centralized heat supply, hot water supply, circulation rate, heat calculator, heat energy consumption, hot water consumption

\section{Introduction}

There is an expression that the greater part of hot water consumption in the total volume of water consumption is observed, the higher the civilization of society is. Indeed, a civilized person during the day repeatedly uses hot water for various purposes and the costs of this invention are becoming more tangible.

Different countries carry out the solution of technical and economic issues of hot water supply (hereinafter DHW) by their own methods, which is quite obvious, given the

\footnotetext{
* Corresponding author: vgnovoseltsev@yandex.ru
} 
features, history, mentality. European countries serve as a definite model and example for Russia, taking into account the specifics of the country.

In literature you can find a lot of data on the successful implementation of energyefficient buildings and monitoring the operation of their engineering systems [1-4]. Experience has been gained both in the design and operation of the hot water supply systems of residential buildings, but, nevertheless, many problems have not yet been resolved, one of which is considered in this article.

The modern district heating system of a residential building is based on an energyefficient and resource-saving individual heating station, which is designed and manufactured by well-known manufacturers of heat energy equipment [5, 6]. Hot water boils at such a point and supplied to the consumer. Regulatory documents and practical wisdom provide for a domestic hot water system with circulation in modern buildings, i.e. when the consumer opens the tap, the water is almost hot. This big advantage has a significant side effect - necessity to organize the circulation process, which requires additional costs, both labor and material [7].

Dead-end DHW systems, which are typical for old buildings, however, exist at present. The advantage is simplicity and relative cheapness, the disadvantage is the useless discharge of chilled water into the sewer while waiting for warm. The transformation of the deadlock system into a circulation (reconstruction) is unlikely, because the layout of old buildings does not provide for the installation of additional pipelines and the placement of appropriate equipment. Plus, the issue of financing reconstruction, search and determination of investment conditions.

A separate niche in Russia is occupied by centralized hot water supply systems as part of the four-pipe design of a heating system for residential buildings with a heat source in the form of a boiler room or central heating station - a central heating center. The presence of the supply and return pipes in the DHW system automatically creates the basis for circulation, but the different distance of the objects from the heat source and their heathydraulic heterogeneity creates difficulties in balancing. Such a branched system combines the features of both a dead end and a ring network. The dead end is characterized by the branching and unambiguous flow direction, the ring one includes the interaction of the supply and return branches with an unstable flow of hot water.

Despite the complexity of such networks, they are very successfully operated in singleindustry towns, small settlements, often with intuitively found system parameters and an optimal radius of heat supply, both for heating and hot water. At the same time, overflows do not occur precisely in the period of transitional temperature, approximately $+8{ }^{0} \mathrm{C}--1 \ldots$ $-5{ }^{0} \mathrm{C}$, when the temperature in the return line is less than $70{ }^{\circ} \mathrm{C}$, and the temperature of hot water must be provided at least $60{ }^{\circ} \mathrm{C}$ according to the norms.

But in most situations when four-pipe heat supply systems operate from a single heat source, problems arise and can be solved both by general recommendations and by applying an individual approach. One of the problems is taking into account the amount of thermal energy for heating hot water, assessing the accuracy of such measurements, comparing the results with standard specific indicators [8].

Many residential buildings are equipped with multi-channel heat meters SPT 961 [9], which measure electrical signals corresponding to the parameters of the heat carrier transported through pipelines and calculate the thermal characteristics and amount of heat carrier. It is also feasible to process data, archive and process it using standard interface tools for the purpose of system analysis.

From the variety of technical and operational parameters that fully comply with operating conditions, we can distinguish metrological indicators characterizing the accuracy of measuring time, pressure, flow and thermal energy, shown in table 1. 
Table 1. Metrological parameters of the heat calculator SPT961

\begin{tabular}{|l|l|}
\hline Name of the parameter of the heat calculator SPT961 & Parameter value \\
\hline watch error (fractional) & $\pm 0,01 \%$ \\
\hline parameters' processing (fractional error) & $\pm 0,02 \%$ \\
\hline $\begin{array}{l}\text { thermal energy calculation } \\
\text { (fractional error)* } \\
\text { *according to the results of input signals measurements }\end{array}$ & $\pm(0,5+3 / \Delta \mathrm{T}) \%$ \\
\hline
\end{tabular}

Attention should be paid to the calculation of the relative error of thermal energy, which is an integrated indicator of input signals with different errors, both relative and absolute. The parameter $\Delta \mathrm{T}$ must be understood as the temperature difference in the mains of the supply and return heat network (or hot water supply network).

Consumers of hot water in apartments install conventional meters such as SV-15G, which are universal and widespread, [10]. According to the parameters of maximum flow rates, pressures and temperatures, they correspond to the hydraulic mode of the DHW network. For the research, the minimum overhead costs, depending on the installation of the meter, are interesting, table 2 . Horizontal installation halves the minimum consumption.

Table 2. Metrological parameters of the individual residential meter SV-15G

\begin{tabular}{|l|l|}
\hline Name of the meter's parameter SV-15G & Parameter value \\
\hline Water consumption $\mathrm{Q}, \mathrm{m}^{3} / \mathrm{h}:$ & \\
Minimal Qmin & \\
Class B (horizontal set) & 0,03 \\
Class A (vertical set) & 0,06 \\
\hline Transition $\mathrm{Q}_{\mathrm{t}}$ & \\
Class B & 0,12 \\
Class A & 0,15 \\
\hline Nominal nomenclature $\mathrm{Q}_{\mathrm{n}}$ & 1,5 \\
Maximum $\mathrm{Qmax}_{\max }$ & 3,0 \\
\hline The limits of permissible relative error, \% & \\
in the range of consumption from $\mathrm{Q}_{\min }$ to $\mathrm{Q}_{\mathrm{t}}$ & \pm 5 \\
in the range of consumption from $\mathrm{Q}_{\mathrm{t}}$ to $\mathrm{Q}_{\max }$ included & \pm 2 \\
\hline Threshold of sensitivity & not more than $0,5 \mathrm{Q}_{\min }$ \\
\hline
\end{tabular}

As an object of research, we consider a residential 144-apartment 9-floor building with a hot water circulation system, equipped with a common heat meter SPT 961, manufactured by AOZT NPF Logika, St. Petersburg. This device is included in the Federal Information Fund for Ensuring the Uniformity of Measurements, verified and equipped with all the necessary interface. The aim of the research is to determine the design and real costs of thermal energy for hot water supply (hot water heating) and their comparison, analysis of the data obtained.

\section{Methods}

\subsection{Methods of research}

The methodology for determining the design and real costs of thermal energy for hot water supply was to study the operation of the facility's hot water supply system. Stages of implementation: project documentation study; inspection of the system in order to identify their technical condition, compliance with design decisions and proper functioning; processing the received data. 


\subsection{Description of design choice for the investigated object.}

The DHW system of the facility provides the following solutions. The hot water supply system is made with individual circulating risers at each water riser, with sequential connection of heated towel rails installed on the circulation riser. The connection of the domestic hot water system of a residential building is carried out directly to the external DHW networks in a two-pipe version. External DHW networks are connected to the central heating center (DHC), which provides direct supply of hot water of the required quality to consumers.

\subsection{Determination of heat energy consumption.}

The methodology for determining the thermal energy consumption at the initial stage was based on the well-known approach combining a total sum of hydraulic calculation, empirical data, and elements of probability calculus. This methodology was given in SNiP 2.04.01-85 * "Internal water supply and sewerage of buildings", which is not currently used, but designers and testers still prefer this technique, because it gives good convergence and is tested by time and practice.

This calculation is necessary at the preliminary stage of determining the diameters of the DHW supply pipelines under the assumption that there is no circulation. For dead-end systems, such a calculation is sufficient; for systems with circulation, further adjustment is necessary taking into account the circulation method. The basic input data and calculation results are shown in table 3 .

Table 3. Consumption of hot water and heat for its heating

\begin{tabular}{|c|c|c|}
\hline Total number of hot water consumers in the building, person & $\mathrm{U}$ & 387 \\
\hline The total number of water intake devices in the building, inits & $\mathrm{N}$ & 432 \\
\hline The likelihood of sanitary appliances in the building & $\mathrm{P}$ & 0,0124 \\
\hline $\mathrm{NP}(\mathrm{N}$ times $\mathrm{P})$ & NP & 5,38 \\
\hline Coefficient $\alpha$ (selected from empirical tables or approximated) & $\alpha$ & 2,693 \\
\hline The maximum second water flow rate at the DHW inlet to the building, $1 / \mathrm{s}$. & $\mathrm{q}^{\mathrm{h}}$ & 2,524 \\
\hline $\begin{array}{l}\text { The probability of using the total number of devices served by the designed } \\
\text { system }\end{array}$ & $\mathrm{Phr}_{\mathrm{hr}}$ & 0,045 \\
\hline NP $(\mathrm{N}$ times $\mathrm{P})$ & $\mathrm{NP}_{\mathrm{hr}}$ & 19,35 \\
\hline Coefficient $\alpha$ (selected from empirical tables or approximated) & $\alpha_{\mathrm{hr}}$ & 6,374 \\
\hline Maximum hourly consumption of hot water, $\mathrm{m}^{3} / \mathrm{h}$. & $\mathrm{q}_{\mathrm{hr}}^{\mathrm{h}}$ & 6,374 \\
\hline $\begin{array}{l}\text { Average hourly consumption for the period (day) of maximum water } \\
\text { consumption, } \mathrm{m}^{3} / \mathrm{h} \text {. }\end{array}$ & $\mathrm{qT}_{\mathrm{T}}^{\mathrm{h}}$ & 1,935 \\
\hline Average hourly water consumption for an average day, $\mathrm{m}^{3} / \mathrm{h}$. & $\mathrm{q}_{\mathrm{T}, \mathrm{m}}^{\mathrm{h}}$ & 1,693 \\
\hline $\begin{array}{l}\text { The average hourly heat flow for the period (day) of maximum water } \\
\text { consumption (taking into account heat losses),kW. }\end{array}$ & $\mathrm{QT}_{\mathrm{T}}^{\mathrm{h}}$ & 148,1 \\
\hline Maximum heat flux during an hour of maximum heat consumption, $\mathrm{kW}$. & $\mathrm{Qhr}^{\mathrm{h}}$ & 488,0 \\
\hline Average hourly heat flux for an average day, $\mathrm{kW}$. & $\mathrm{Q}_{\mathrm{T}, \mathrm{m}^{\mathrm{h}}}$ & 129,6 \\
\hline
\end{tabular}


The design scheme for one entranceway of 36 apartments with 9 floors is shown in Figure 1. Each supply riser is looped with a circulation riser, heated towel rails are located on the circulation branches.

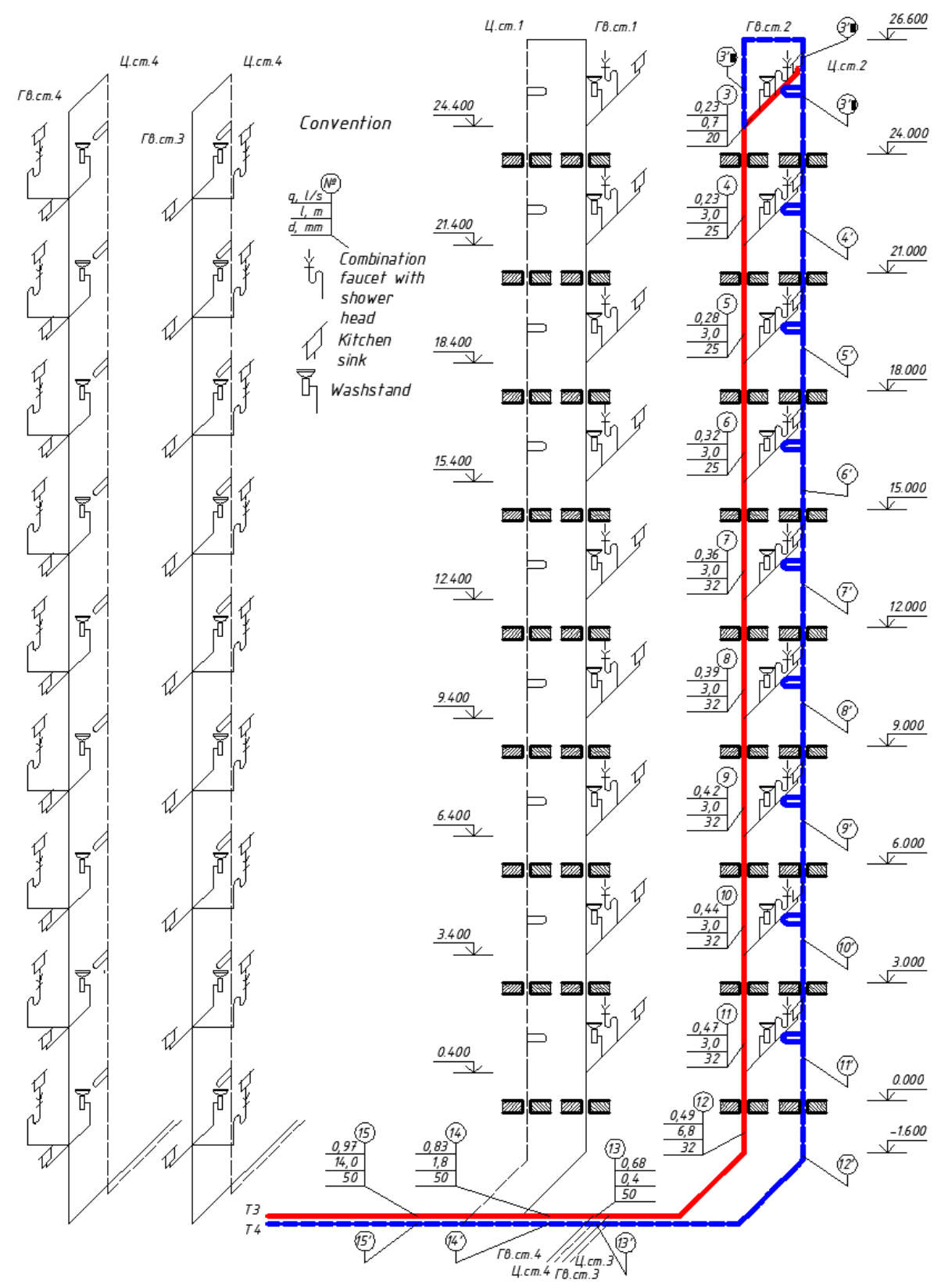

Fig. 1 Design scheme of the hot water supply system of one entranceway of a 9-floor building 
After calculating the main parameters, the result of table 3, the calculation of the circulation costs of the DHW network. The circulation flow rate is calculated according to standard formulas and depends on the length, diameters of the pipelines, the circulation pattern, the type and state of thermal insulation, the temperature difference in the supply and return (circulation) lines, the results are shown in table 4.

Table 4. Calculation of the circulation costs of the 36 apartments' entranceway of a 9- floor building

\begin{tabular}{|c|c|c|c|c|c|c|c|}
\hline \multirow[b]{2}{*}{ № land } & \multirow[b]{2}{*}{$\mathrm{L}, \mathrm{m}$} & \multirow[b]{2}{*}{$\underset{\mathrm{m}}{\mathrm{d}, \mathrm{m}}$} & \multicolumn{3}{|c|}{ Loss of heat } & \multirow{2}{*}{$\begin{array}{l}\text { Circulatio } \\
\text { n rate } \mathrm{q}^{\mathrm{cir}} \\
\qquad 1 / \mathrm{s}\end{array}$} & \multirow{2}{*}{$\begin{array}{c}\text { Circulatio } \\
\text { n rate } \mathrm{q}^{\mathrm{cir}}, \\
1 / \mathrm{s}\end{array}$} \\
\hline & & & $\begin{array}{l}\text { Specificall } \\
\text { y q, W/m }\end{array}$ & $\begin{array}{c}\text { On a land } \\
\text { Qht, W }\end{array}$ & $\begin{array}{c}\text { Sum } \Sigma Q^{\text {ht }} \\
\text { W }\end{array}$ & & \\
\hline \multicolumn{8}{|c|}{ In-house wiring } \\
\hline $1-2-3$ & 2,3 & 20 & 24 & 1405,20 & 1405,20 & 0,034 & 0,05 \\
\hline 4 & 3 & 25 & 12,6 & 37,80 & 1443,00 & 0,035 & 0,05 \\
\hline 5 & 3 & 25 & 12,6 & 37,80 & 1480,80 & 0,036 & 0,05 \\
\hline 6 & 3 & 25 & 12,6 & 37,80 & 1518,60 & 0,037 & 0,05 \\
\hline 7 & 3 & 32 & 13,9 & 41,70 & 1560,30 & 0,038 & 0,05 \\
\hline 8 & 3 & 32 & 13,9 & 41,70 & 1602,00 & 0,039 & 0,05 \\
\hline 9 & 3 & 32 & 13,9 & 41,70 & 1643,70 & 0,040 & 0,05 \\
\hline 10 & 3 & 32 & 13,9 & 41,70 & 1685,40 & 0,041 & 0,05 \\
\hline 11 & 3 & 32 & 13,9 & 41,70 & 1727,10 & 0,042 & 0,05 \\
\hline 12 & 6,8 & 32 & 19,1 & 129,88 & 1856,98 & 0,045 & 0,05 \\
\hline $\mathrm{C}_{\mathrm{T}, 3}$ & & & & & 1822,60 & 0,044 & \\
\hline 13 & 0,387 & 50 & 24,1 & 9,33 & 3688,91 & 0,089 & 0,10 \\
\hline $\mathrm{C}_{\mathrm{T}, 4}$ & & & & & 1822,60 & 0,044 & \\
\hline 14 & 1,8 & 50 & 24,1 & 43,38 & 5554,89 & 0,135 & 0,15 \\
\hline Ст, 1 & & & & & 1822,60 & 0,044 & \\
\hline 15 & 14 & 50 & 24,1 & 337,40 & 7714,89 & 0,187 & 0,20 \\
\hline
\end{tabular}

Consequently, the circulating flow rate for the house under study (4 entranceway) will amount to a small fraction $\mathrm{G}_{\mathrm{\Perp}}=4 \times 0,2=0,8 \mathrm{l} / \mathrm{s}=2,88 \mathrm{~m}^{3} / \mathrm{h}=2,88 \times 0,9835=2,83 \mathrm{tph}$.

\section{Results and discussion}

The above SPT 961 heat meter installed in the building measures the following parameters of the DHW system:

Gn, Go - mass flow rate for supply and return, tph;

Vп, Vo - volumetric flow rate for supply and return, $\mathrm{m}^{3} / \mathrm{h}$;

Тп, To - flow and circulation temperatures respectively, ${ }^{\circ} \mathrm{C}$;

Рп, Ро - supply and return pressure, $\mathrm{kg} / \mathrm{cm}^{2}$;

$\mathrm{dM}$ - network mass flow, tph;

$\mathrm{dW}$ - thermal power, Gcal/h;

$\mathrm{dV}$ - volume difference, $\mathrm{m}^{3} / \mathrm{h}$;

$\Delta$ - quotient from dW divided $\mathrm{dV}, \mathrm{Gcal} / \mathrm{m}^{3}$ 
Below there are the results of measuring the main parameters of the DHW system during the day. The time interval is selected for the period of the normal rhythm of life, a working day in the middle of the week in order to exclude non-standard mode of water consumption. The measurement results are shown in table 5.

Table 5. The results of the main parameters of the DHW system measurements during the day

\begin{tabular}{|c|c|c|c|c|c|c|c|c|c|c|c|c|}
\hline $\begin{array}{l}\text { Measure- } \\
\text { ment time }\end{array}$ & Gп & Go & $V_{\Pi}$ & Vo & Тп & To & $P_{\Pi}$ & Po & $\mathrm{dM}$ & $\mathrm{dW}$ & $\mathrm{dV}$ & $\Delta$ \\
\hline $\mathrm{h}$ & tph & $\mathrm{T} / \mathrm{h}$ & $\mathrm{m}^{3} / \mathrm{h}$ & $\mathrm{m}^{3} / \mathrm{h}$ & ${ }^{0} \mathrm{C}$ & ${ }^{0} \mathrm{C}$ & $\mathrm{ko} / \mathrm{cm}^{2}$ & $\mathrm{ko} / \mathrm{cm}^{2}$ & tph & $\mathrm{Gcal} / \mathrm{h}$ & $\mathrm{m}^{3} / \mathrm{h}$ & $\begin{array}{c}\text { Gcal } \\
/ \mathrm{m}^{3}\end{array}$ \\
\hline :00:00 & 57 & 3,16 & 3,63 & 3,20 & 59,31 & 49,44 & 6,28 & 6,18 & 0,41 & 0,05 & 0,43 & 0,1163 \\
\hline 00 & 50 & 25 & 3,43 & 3,28 & 9,10 & 49,30 & 6,31 & 25 & 13 & 0,04 & 15 &, 2667 \\
\hline 02:00:00 & 19 & 3,19 & 3,24 & 3,22 & 58,88 & 49,13 & 6,32 & 6,24 & 0,00 & 0,03 & 0,02 & 1,5000 \\
\hline 3:00:00 & 19 & 19 & 3,24 & 3,23 & 58,72 & 9,00 & 6,33 & 25 & 0,00 & 0,03 & 0,01 & 3,00 \\
\hline 1:00:00 & 21 & ,19 & 3,26 & 3,22 & 8,63 & 48,88 & , & 6,25 & 0,02 & 0,03 &, 04 & 0,75 \\
\hline :00:00 & 0 & 3,19 & 3,25 & 3,22 & 52 & 8,85 & 6,33 & 5,24 & 02 & 0,03 & 03 & 1,0000 \\
\hline 06:00:00 & 3,44 & 3,12 & 3,49 & 3,16 & 58,68 & 48,88 & 6,31 & 6,22 & 0,31 & 0,05 & 0,33 & 0,1515 \\
\hline 0:00 & 4,11 & 05 & 4,17 & 3,08 & 3,93 & 399 & 6 & 12 & 1,06 & 0,09 & 1,09 & 0,08 \\
\hline .00 .00 & Ji & 08 & 4,13 & 5,11 & 9,29 & L & 0 & IJ & 0,99 & 0,08 & 1,02 & 0,0784 \\
\hline 9:00:00 & 94 & 3,11 & 4,01 & 15 & 9,42 & 49,47 & 6,25 & 15 & 83 & 0,07 & 0,86 & 0,0814 \\
\hline \begin{tabular}{|l|}
$10: 00: 00$ \\
\end{tabular} & 88 & 3,13 & 3,94 & 3,16 & 59,47 & 49,59 & 6,25 & 6,15 & 0,75 & 0,07 & 0,78 & 0,0897 \\
\hline $0: 00$ & & 17 & 3,81 & 0 & 4 & 49,48 & 6,26 & 6,16 & 0,59 & 0 , & 61 & 0,0 \\
\hline 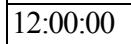 & ,62 & 23 & 3,68 & 27 & 22 & 49,48 & 6,27 & 6,17 & 39 & 0,0 &, 41 & 0,1220 \\
\hline \begin{tabular}{|l|}
$13: 00: 00$ \\
\end{tabular} & 3,77 & 3,24 & 3,83 & 3,27 & 59,21 & 49,44 & 6,27 & 6,16 & 0,54 & 0,06 & 0,56 & 0,1071 \\
\hline 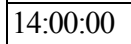 & 58 & 20 & 3,74 & 3,24 & 59,18 & 49,41 & 6,28 & 6,18 & 0,47 & 0,06 & 0,50 & 0,1200 \\
\hline \begin{tabular}{|l|}
$15: 00: 00$ \\
\end{tabular} & 3,49 & 3,20 & 3,54 & 3,23 & 59,10 & 47,24 & 0,20 & 17 & 0,29 & 0,07 & 0,31 & 0,1290 \\
\hline 16:00:00 & 3,53 & 17 & 3 & 0 & 2 & 49,18 & 6,28 & 0,18 & 36 & 0,05 & 38 & 1316 \\
\hline 17:00:00 & 3,61 & 3,16 & 3,67 & 3,20 & 59,04 & 49,14 & 6,27 & 6,18 & 0,45 & 0,06 & 0,47 & 0,1277 \\
\hline \begin{tabular}{|l|}
$18: 00: 00$ \\
\end{tabular} & 3,70 & 3,17 & 3,76 & 3,20 & 59,09 & 49,17 & $0,2 J$ & 6,15 & 0,54 & 0,06 & 0,56 & 0,1071 \\
\hline 19:00:00 & 00 & 3,06 & 4,12 & 3,09 & 5007 & 年 & 50 & 612 & 1,00 & (1) & 1,03 & 0,07 \\
\hline $20: 00: 00$ & 4,10 & 3,10 & 4,16 & 3,14 & 59,36 & 49,19 & 6,22 & 6,11 & 0,98 & 0,08 & 1,02 & 0,0784 \\
\hline $21: 00: 00$ & 4,31 & 3,03 & 4,38 & 3,06 & 59,49 & 49,30 & 6 , & 09 & 1,29 & 0,10 & 1,32 & 0,0758 \\
\hline 2L.00.00 & 4,45 & 2,96 & 4,52 & 2,99 & 59,63 & 49,42 & $0, \angle 1$ & 6,10 & 1,49 & 0,10 & 1,53 & 0,0654 \\
\hline 23:00:00 & 3,84 & 3,14 & 3,90 & 3,17 & 59,53 & 49,51 & 6,25 & 6,15 & 0,71 & 0,07 & 0,73 & 0,0959 \\
\hline
\end{tabular}

Based on the results of table 5, graphical dependencies are plotted as shown in Figure 2. 


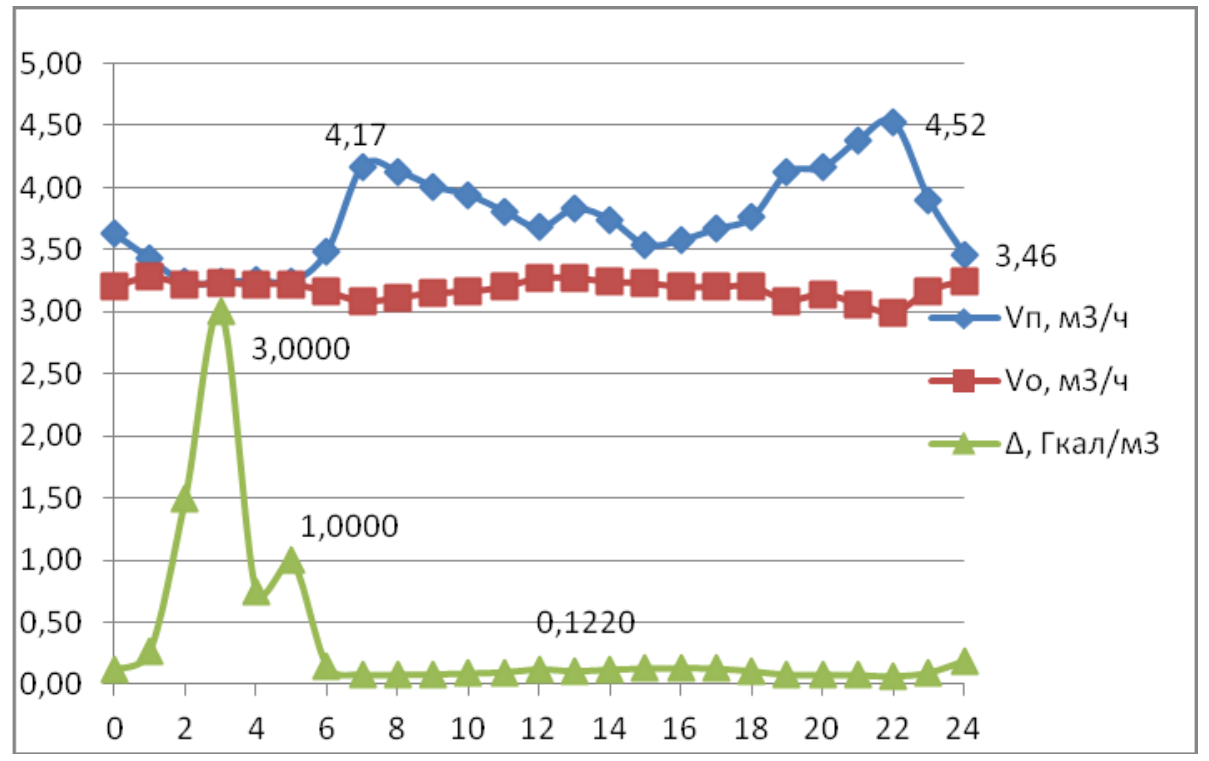

Fig 2. Change of

The same dependencies are also built for other houses and for different periods of time, which can characterize the mode of consumption of hot water and the features of the domestic hot water system. For an example the most characteristic house has been selected.

The hourly average flow rate of hot water is taken as the base point, as second consumption is not of practical value for operating organizations. And registering apparatus are not tuned to such delicate and accurate measurements.

The average hourly volumetric flow rate of hot water is determined as the difference Vח - Vo. The values of Vח and Vo are taken according to the readings of heaters SPT 961. On the other hand, the average hourly volumetric flow rate of hot water is the sum of the costs of water collection and circulation, and the terms constantly change over time and are determined by the nature of hot water consumption for a particular building. This is the volume, number of floors, the degree of improvement, the number of residents and their structure (age, mentality, degree of employment, etc.).

The peculiarity lies in the fact that the water draw-off is taken into account by individual water meters with a sufficient degree of accuracy, and the circulation flow is taken into account by a house-building, the degree of accuracy of which may be insufficient. Any consumption of hot water requires heating and pump circulation, i.e. material and financial costs. Not only technical, but economic and, in some way, political issue appears.

On the technical side, the analysis of the presented dependencies made it possible to distinguish the following modes during the average consumption day:

1. Circulation, time $01.00-06.00$. There is almost no hot water draw-off, the maximum circulation is $[0.01-0.33] \mathrm{m}^{3} / \mathrm{h}$. The indicator $\Delta[0,1515-3,000] \mathrm{Gcal} / \mathrm{m}^{3}$.

2. Water intake - circulation, time $14.00-16.00,18.00$. Water intake and circulation are carried out simultaneously within the dynamically changing range of $[0.26-0.66] \mathrm{m}^{3} / \mathrm{h}$. The indicator $\Delta[0.1053-0.1282] \mathrm{Gcal} / \mathrm{m}^{3}$.

3. Water intake, time $7.00-13.00,17.00,19.00-00.00$. Water intake and circulation are carried out simultaneously, and the circulation is minimal $[0.06-0.1] \mathrm{m}^{3} / \mathrm{h}$. The indicator $\Delta$ $[0,07527-0,09589] \mathrm{m}^{3} / \mathrm{h}$. 


\section{Conclusion}

Centralized DHW systems are characterized by a significant length and branching, which inevitably leads to increased heat losses, and to an unstable hydraulic regime.

Domestic hot water systems of buildings have different number of storeys and sizes, variable hydraulic resistance, are directly hydraulically connected to external networks, being their continuation. Hydraulic balancing should be carried out both along the internal circuit and the external, which is a difficult task.

The modes of water analysis of the domestic hot water supply network are variable in time, circulation, circulation-water analysis, water analysis can vary by week, month and season, and may not coincide in time with other internal systems. Heat losses are almost constant throughout the day, the flow of hot water varies from the minimum circulation flow to the maximum flow rate.

The operation of the domestic hot water system in the circulation mode can be characterized by several parameters, one of which $\Delta$ is the specific ratio of the cost of thermal energy for heating a cubic meter of hot water. This parameter is often regulated by law at the levels of the city, region, i.e. at the local level. Exceeding this parameter is administratively punishable.

The full circulation time, as a rule, is night hours, constant heat loss with a minimum consumption of hot water. Heat losses can be reduced, but there is the concept of the optimal thickness of thermal insulation, normalized heat flux density. Then it is necessary to increase the consumption of hot water to reduce the standard for heating a cubic meter of water.

The analysis has showed that in present situation the circulation flow does not exceed $0.43 \mathrm{~m}^{3} / \mathrm{h}$, or $0.42 \mathrm{t} / \mathrm{h}$. As noted above, the estimated circulating flow rate is at least $2 \mathrm{t} / \mathrm{h}$. Therefore, to optimize the heating standard of a cubic meter of water, it is necessary to observe the calculated circulation modes. This will require stabilization of the hydraulic modes of both the external and internal networks, which is a difficult but feasible task.

\section{References}

1. L. Zhang, O. Gudmundsson, J.E. Thorsen, H. Li, S. Svendsen 2014 Energy Procedia 64 2833-2840

2. T. Kitzberger, D. Kilian, J. Kotik, T. Pröll 2019 Energy and Buildings 195 126-138

3. J. An, D. Yan, G. Deng, R. Yu 2016 Energy and Buildings 133 321-334

4. S. Werner 2017 Energy 126 419-429

5. V.M. Melnikov, M.V. Shenogin 2019 Innovations and Investments 1 209-212 (in Russian)

6. E.A. Biriuzova, K.I. Ogurtsova 2012 Herald of civil engineers 4 (33) 188-192 (in Russian)

7. U. Navaseltsau, D. Navaseltsava, I. Chernikov 2016 Bulletin of the Brest State Technical University: Water construction, heat power engineering, geoecology 2 81-84. (in Russian)

8. V.S. Mokrousov, A.G. Manov, V.M. Melnikov (2012) The system of accounting and regulation of heat energy consumption by subscribers Russian Federation Utility Model Patent No. RU 112410 U1, 10.01.2012 Moscow: The Russian Federal Service for Intellectual Property

9. Heat meter SPT961 (mod. 961.2) (2020) Retrieved from http://www.логика.pф/catalog/1/370/

10. SV-15G, SV-15X hot and cold water meters (2020) Retrieved from http://теплоприбор.pф/catalog/sv-15/ 